1 Dickersin GR. The ultrastructure of selected gynecologic neoplasms. Clin Lab Med 1987;7:117-56

2 Matsumoto E, Muragaki Y, Ooshima A. Increased amoun of serum type IV collagen peptide in human liver fibrosis as determined by enzyme-immunoassay with monoclonal antibodies. Acta Pathol Fpn 1989;39:217-23.

3 Stenbäck F, Wasenius V-M. Basement membrane structures in tumors of the ovary. Eur $\mathcal{F}$ Obstet Gynecol Reprod Biol 1985;20:357-71.

4 Meng N, Nakashima N, Nagasaka T, Fukatsu T, Nara Y, Yoshida $\mathrm{K}$, et al. Immunohistochemical characterization of extracellular matrix components of granulosa cell tumor of extracellular matrix components of

5 Rajah R, Sundaram GS. Protein distribution and gene expression of collagen type IV in the neonatal rat ovary during follicle formation. Cell Mol Biol 1994;40:769-80.
6 Schneider M, Voss B, Hogemann B, Eberhardt G, Gerlach U. Evaluation of serum laminin P1, procollagen-III peptides and N-acetyl-b-glucosaminidase for monitoring the activity of liver fibrosis. Hepatogastroenterology 1989;36:506-10.

of liver fibrosis. Hepatogastroenterology 1989;36:506-10.
Niemela O, Risteli L, Sotaniemi EA, Risteli J. Type IV collagen and laminin-related antigens in human serum in alcoholic liver disease. Eur $\mathcal{F}$ Clin Invest 1985;15:132-7.

8 Brocks DG, Strecker H, Neubauer HP, Timple R. Radioimmunoassay of laminin in serum and its application to cancer patients. Clin Chem 1986;32:787-91.

9 Biegelmayer C, Feiks A, Rudelstorfer R. Laminin in pregnancy. Gynecol Obstet Invest 1986;22:7-11

10 Hahn E, Wick G, Pencev D, Timpl R. Distribution of basement membrane proteins in normal and fibrotic human liver: collagen type IV, laminin and fibronectin. Gut 1980;21:63-71.

\title{
Inflammatory pseudotumour and Rosai-Dorfman disease of soft tissue: a histological continuum?
}

\author{
D Govender, R Chetty
}

\begin{abstract}
A lesion of the chest wall in a 34 year old woman, which had a combination of histological and immunophenotypic features of inflammatory pseudotumor and Rosai-Dorfman disease of soft tissue, is described. There was considerable overlap in the pathogenesis, histology and immunophenotype of these two lesions. The similarities between these two lesions suggest that there is a temporal sequence and a histological continuum with early histiocyte-rich and late fibroblast- and myofibroblast-rich lesions. Alternatively, the morphological and immunophenotypic features could be because of aberrant cytokine expression in an inflammatory pseudotumour, resulting in transformation of histiocytes to resemble those seen in Rosai-Dorfman disease. ( Clin Pathol 1997;50:79-81)
\end{abstract}

Keywords: inflammatory pseudotumour; RosaiDorfman disease; histiocytosis.

Sinus histiocytosis with massive lymphadenopathy (SHML or Rosai-Dorfman disease (RDD)) was first described as a distinct clinicopathological entity that presents with striking lymph node enlargement, often affecting the cervical lymph nodes. It has subsequently been reported in extranodal sites (skin, soft tissues, bone, and nasal mucosa) in up to $43 \%$ of reported cases. ${ }^{1}$ Histologically, this condition is characterised by a proliferation of large pale cells which show striking lymphocytophagocytosis and immunoreactivity for $\mathrm{S} 100$ protein. ${ }^{1}$ The histogenesis of the proliferating cell is uncertain but it has features of both Langerhans cells and phagocytes.
Inflammatory pseudotumour is the preferred term for a tumour-like mass of inflammatory origin, which has been reported in various organs and sites. Several other terms, such as plasma cell granuloma, xanthomatous pseudotumour, fibrous xanthoma, inflammatory myofibrohistiocytic proliferation and inflammatory myofibroblastic tumour ${ }^{2}$ have also been used to describe this lesion. The aetiology and nosology of this lesion remain uncertain. The majority of inflammatory pseudotumours are idiopathic. The lesion is usually excised because the clinical and radiological appearances often suggest malignancy.

We report an unusual soft tissue lesion in a 34 year old Asian woman which showed a combination of features of inflammatory pseudotumour and Rosai-Dorfman disease of soft tissue. We suggest that these two lesions are part of a spectrum of inflammatory or reactive conditions, or both, occurring in soft tissues.

\section{Case report}

A 34 year old woman presented with a $2 \mathrm{~cm}$ superficial, firm, mass on the chest wall of short duration. There were no enlarged lymph nodes. She had had a splenectomy 15 years earlier. The reason for the splenectomy was unknown. Laboratory investigations revealed a normocytic normochromic anaemia. There were no other significant findings on history, physical examination and blood investigations. The mass was excised with a wide margin.

The patient is well without any evidence of recurrence or lymphadenopathy six months after resection.

\section{Methods}

The tissue was fixed in formalin and processed for histological examination. Immunohistochemical studies were done on formalin fixed, 


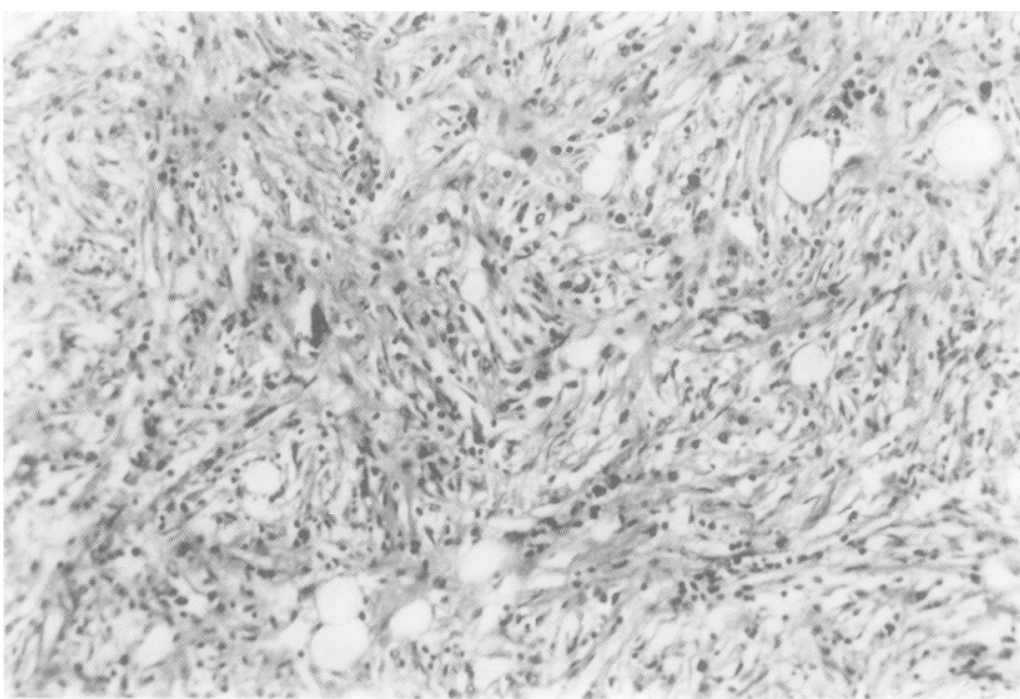

Figure 1 Inflammatory pseudotumour. Proliferating spindle cells with admixed lymphocytes and plasma cells (haematoxylin and eosin; original magnification $\times 200$ ).

paraffin wax embedded tissue using the streptavidin-biotin-peroxidase complex method (Universal LSAB/HRP kit, Dako, Glostrup, Denmark) with 3,3'diaminobenzidine (DAB) (liquid 3,3'diaminobenzidine substrate chromogen kit, Dako) as the chromogen.

Antibodies used were: S100 protein (polyclonal, Signet Laboratories, Dedham, Massachusetts, USA; diluted 1 in 300); Mac 387 (Dako; diluted 1 in 100), CD68 (KP1, Dako; diluted 1 in 100); vimentin (V9, Signet Laboratories; diluted 1 in 10); muscle specific actin (HHF35, Biogenix, San Ramon, California, USA; prediluted); CD79a (JCB1 17, Dako; diluted 1 in 30); CD20 (L26, Dako; diluted 1 in 100); CD3 (polyclonal, Dako; diluted 1 in 40); UCHL-1 (Dako; diluted 1 in 120); LMP1 (CS1-4, Dako; diluted 1 in 40); $\kappa$ light chain (polyclonal, Signet Laboratories; diluted 1 in 3000); and $\lambda$ light chain (polyclonal, Signet Labatories, diluted 1 in 2000).

Sections were microwaved for 10 minutes at $85^{\circ} \mathrm{C}$ in a $0.01 \mathrm{M}$ sodium citrate buffer solution to enhance antigen retrieval and immunoreactivity.

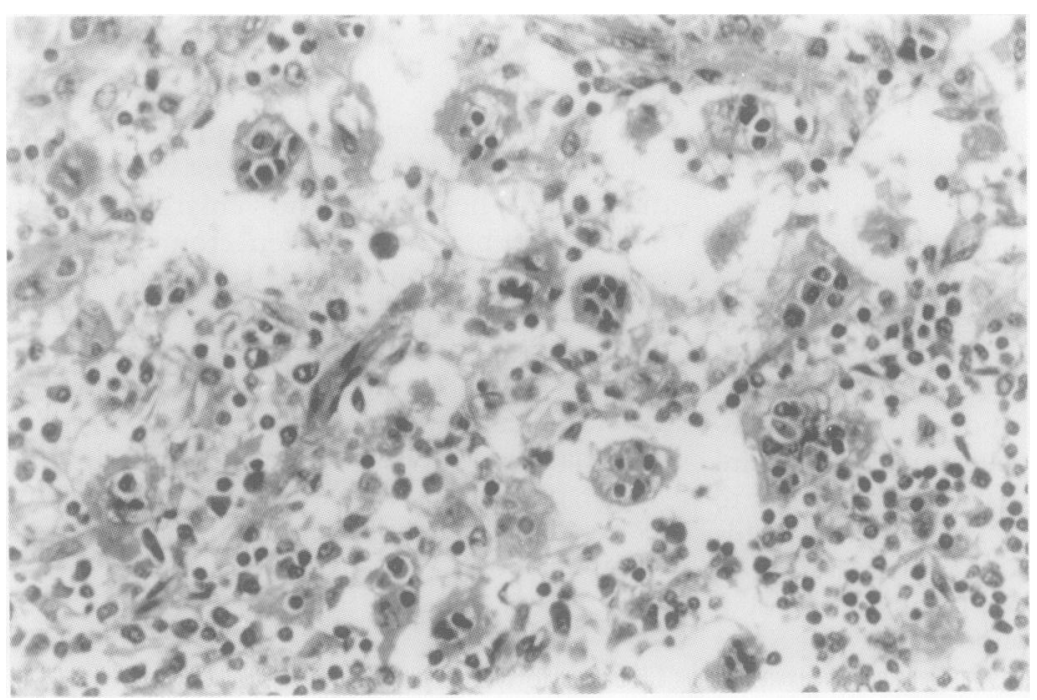

Figure $2 R D D$-like area with large histocyte-like cells exhibiting prominent emperipolesis of lymphocytes and plasma cells (haematoxylin and eosin, original magnification $\times 400$ ).

\section{Results}

The specimen measured $3 \times 3 \times 2 \mathrm{~cm}$. Cut sections revealed a $2 \mathrm{~cm}$ solid, gray, poorly defined mass. Microscopic examination showed a poorly circumscribed lesion composed predominantly of spindle cells arranged in poorly formed fascicles and focal storiform areas. These cells had eosinophilic cytoplasm, indistinct cell borders and elongated nuclei with tapering ends. Lymphocytes, plasma cells and histiocytes were intermixed with the spindle cells (fig 1). Few mitotic figures were present. In some areas the periphery of the lesion had an infiltrative appearance with extension into the adjacent adipose tissue. Also present were randomly distributed, vaguely nodular areas within the lesion that merged with the spindle cell areas. These areas consisted of a dense infiltrate of lymphocytes and plasma cells. Numerous large, pale histiocytes were prominent in this area (fig 2). A distinctive feature of this cell was intracytoplasmic lymphocytes surrounded by a clear halo (fig 2). Plasma cells, neutrophils and occasional red blood cells were also phagocytosed. There was no necrosis. Breast lobules and ducts were not present in the specimen, suggesting that the lesion was confined to the subcutis and deep soft tissue.

The spindle cells were immunoreactive for vimentin and CD68 (KP1). They were also focally positive for $S 100$ protein and muscle specific actin, but negative for desmin. The histiocytes showed strong immunoreactivity for S100 protein, CD68 (KP1) and Mac 387. The lymphocytes consisted of a mixture of $B$ and $T$ cells. The plasma cell population was polyclonal. There was no expression of LMP-1.

\section{Discussion}

Although the histogenesis of the proliferating cell in SHML/RDD is uncertain, the immunophenotype of this cell has been determined. ${ }^{3}$ The SHML cell expresses $S 100$ protein similar to Langerhans cells but also has regular nuclei and shows prominent phagocytosis, in contrast to Langerhans cells. It has been suggested that the SHML cells are functionally activated macrophages.

At present, SHML is classified as a primary histiocytosis ${ }^{1}$ beacuse of an aberrant immune response. SHML has been reported in patients with lymphoproliferative disorders, including six cases associated with non-Hodgkin's lymphoma ${ }^{1}$ and Hodgkin's disease. ${ }^{4}$ There may or may not be a pathogenetic relation between lymphoproliferative disorders and SHML. It has been postulated that in Hodgkin's disease, neoplastic cells may secrete certain cytokines that stimulate monocytes to become phagocytic histiocytes with the immunophenotype of SHML cells. ${ }^{4}$

Hodgkin's disease and Castleman's disease have been associated with interleukin-6 (IL-6) production. ${ }^{56}$ The similarities in the clinical features of inflammatory pseudotumour, Hodgkin's disease and Castleman's disease have led to the implication of IL- 6 in the pathogenesis of inflammatory pseudotumour. ${ }^{2}$

There is considerable overlap in the histological and immunophenotypic features of 
inflammatory pseudotumour and RDD of soft tissue. In fact, soft tissue RDD needs to be considered in the differential diagnosis of inflammatory pseudotumour. ${ }^{7}$ Emperipolesis is often inconspicuous in RDD of soft tissue and the proliferating histiocytes often assume a spindled morphology. ${ }^{8}$ This, coupled with the accompanying lymphoplasmacytic inflammatory response, heightens the similarity. There are distinct clinical differences between RDD of lymph nodes and RDD in soft tissue: age, sex and clinical outcome are points of departure. $^{8}$

Epstein-Barr virus has been detected in a few cases of inflammatory pseudotumour ${ }^{2}$ and has also been speculated to play a role in the pathogenesis of SHML.' Our case did not demonstrate immunohistochemical staining for LMP-1.

Previous studies have alluded to the relation between the age of the lesion and the degree of cellularity in inflammatory pseudotumour. ${ }^{9}$ Williams et $a l^{10}$ have suggested that initially there is a predominance of KP1 positive cells over vimentin and actin positive cells, but with ageing of the lesion, vimentin and actin positive cells predominate. This translates to a predominance of histiocytic cells in the early stage of the lesion and a predominance of myofibroblasts and fibroblasts in the late lesion. This immunophenotype of histiocytic and myofibroblastic cells has been postulated to be the result of functional adaptive transformation by phagocytic cells. Despite the presence of phagocytic cells in inflammatory pseudotumour, histological evidence of emperipolesis has not been a prominent feature. Another common cellular component of both lesions is a polyclonal population of plasma cells.

Could the lesion we report represent an intermediate stage in the continuum between histiocyte-rich and myofibroblast-rich cell populations, as suggested by Williams et al. ${ }^{10}$ The immunophenotypic profile, in our case, supports the temporal sequence: strongly CD68 and S100 protein positive histiocyte-like cells in the early lesion; spindle cells with CD68 and focal $\$ 100$ protein reactivity in the intermediate lesions; and CD68 and S100 protein negative spindle cells in the late fibroblast and myofibroblast-rich inflammatory pseudotumour.
It is suggested that the histiocyte-rich populations with prominent phagocytosis present in early lesions may result from the presence of an infective agent or some other inflammatory stimulus. The removal of the inflammatory stimulus results in differentiation of cells into myofibroblasts or fibroblasts. However, persistence of the inflammatory stimulus will maintain a histiocyte-rich population.

An alternative hypothesis to explain the case under discussion is that it represents an inflammatory pseudotumour in which aberrant cytokine expression, possibly IL-6 induced by an infectious agent, leads to local transformation of histiocytes or indeterminate cells into RDD cells.

Our case conforms to RDD of soft tissue as described by Montgomery et al in many respects. However, there is a distinct component resembling inflammatory pseudotumour. The pathogenesis, probably mediated by cytokines in response to an infectious agent, is common to both entities and a temporal sequence may occur, accounting for the different morphologies.

1 Foucar E, Rosai J, Dorfman R. Sinus histiocytosis with massive lymphadenopathy (Rosai-Dorfman Disease): Review of the entity. Semin Diagn Pathol 1990;7:19-73.

2 Coffin CM, Watterson J, Priest JR, Dehner LP. Extrapulmonary inflammatory myofibroblastic tumor (inflammatory pseudotumor). Am $\mathcal{f}$ Surg Pathol 1995;19:859-72.

3 Eisen RN, Buckley PJ, Rosai J. Immunophenotypic characterization of sinus histiocytosis with massive lymphadenopathy (Rosai-Dorfman Disease). Semin Diagn Pathol 1990;7:74-82.

4 Falk S, Stutte HJ, Frizzera G. Hodgkin's disease and sinus histiocytosis with massive lymphadenopathy-like changes. Histopathology 1991;19:221-4.

5 Hsu SM, Waldron JA, Xie SS, Barlogie B. Expression of interleukin-6 in Castleman's disease. Hum Pathol 1993;24: 833-9.

6 Hsu SM, Xie SS, Hsu PL, Waldron J Jr. Interleukin-6, but not interleukin- 4 , is expressed by Reed-Sternberg cells in Hodgkin's disease with or without histologic features of Castleman's disease. Am $\mathcal{F}$ Pathol 1992;141:129-38.

7 Chan JKC. Inflammatory pseudotumor: A family of lesions of diverse nature and etiologies. Adv Anat Pathol 1996;3: $156-71$.

8 Montgomery EA, Meis JM, Frizzera G. Rosai-Dorfman disease of soft tissue. Am $\mathcal{F}$ Surg Pathol 1992;16:122-9.

9 Hurt MA, Santa Cruz DJ. Cutaneous inflammatory pseudotumor. Lesions resembling 'inflammatory pseudotumors" or "plasma cell granulomas" of extracutaneous sites. Am F Surg Pathol 1990;14:764-73.

10 Williams SB, Foss RD, Ellis GL. Inflammatory pseudotumors of the major salivary glands. Clinicopathologic and immunohistochemical analysis of six cases. Am $\mathcal{f}$ Surg Pathol 1992;16:896-902. 